\title{
Significant muscle loss following intramuscular corticosteroid injection used to treat active rheumatoid arthritis: a case report
}

Thomas J. Wilkinson ${ }^{1 *}$, Andrew B. Lemmey ${ }^{1}$, Thomas D. O'Brien ${ }^{1,2}$ and Jeremy G. Jones ${ }^{1,3}$

*Correspondence: thomas.wilkinson@bangor.ac.uk

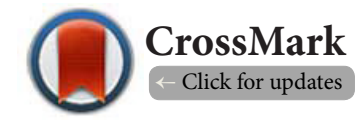

${ }^{1}$ School of Sport, Health and Exercise Sciences, Bangor University, Bangor, United Kingdom.

${ }^{2}$ School of Sport and Exercise Sciences, Liverpool John Moores University, Liverpool, United Kingdom.

${ }^{3}$ Peter Maddison Rheumatology Centre, Llandudno Hospital, Betsi Cadwaladr University Health Board, Wales, United Kingdom.

\begin{abstract}
Introduction: Intramuscular (IM) injection of corticosteroids (CS) is recommended and routinely used to suppress inflammation and relieve pain during an acute episode or exacerbation of rheumatoid arthritis (RA). We present the case of a patient with RA who developed significant muscle loss following an IM CS (triamcinolone acetonide, $40 \mathrm{mg}$ ) injection given for a disease 'flare'.

Case presentation: During a clinical trial assessing the effects of oral creatine monohydrate supplementation, we were able to assess changes to dual x-ray absorptiometry (DXA)-assessed body composition following an IM injection given to one of our patients. Although DAS28 was dramatically improved following the injection, assessment revealed a $2.4 \mathrm{~kg}(4 \%)$ loss of total lean mass (TLM) had occurred, the majority of which occurred in the arms and legs $(2.0 \mathrm{~kg}(7 \%))$.

Discussion: Whilst it is possible that the depletion of LM occurred between the onset of flare and the CS injection, this single case report raises the possibility that the IM CS injection, which is regularly used and recommended as treatment of active RA, may be contributing to the substantial and sudden loss of muscle mass observed.
\end{abstract}

Keywords: Rheumatoid arthritis, muscular atrophy, cachexia, intramuscular corticosteroid injection

\section{Introduction}

Intramuscular (IM) injection of corticosteroids (CS) is recommended and routinely used to suppress inflammation and relieve pain during an acute episode or exacerbation of rheumatoid arthritis (RA) [1]. Although potential adverse events such as increased blood pressure and fat atrophy have been reported following IM CS injection [2], the effects on muscle mass are less well documented. We present the case of a patient with RA who developed significant muscle loss following an IM CS (triamcinolone acetonide, $40 \mathrm{mg}$ ) injection given for a 'flare'.

\section{Case presentation}

A 44-year-old male, with established RA (disease duration 10 years), controlled with leflunomide (20 mg daily), was participating in a clinical trial assessing the effects of oral creatine monohydrate supplementation (a form of protein supplementation designed to increase muscle mass). The primary outcome measure was dual x-ray absorptiometry (DXA)-assessed body composition, and the inclusion criteria were stable disease and medication, with no recent history ( $<3$ months) of CS injection. At the start of the trial, disease was controlled (Disease Activity Score in 28 joints; DAS28 score=2.91). Seven weeks later, his disease 'flared'. Consequently, he consulted his GP who confirmed a 'flare', but did not record a DAS28, and gave an IM CS injection to control this.

Twenty eight days after the injection, the patient was followed up as per the trial protocol; he reported a dramatic improvement in his flare symptoms, and his DAS28 was 1.54. Body composition was re-assessed by DXA (see Table 1). This assessment revealed a $2.4 \mathrm{~kg}(4 \%)$ loss of total lean mass (TLM) in the 12 weeks between baseline and follow-up measures; the majority of which occurred in the arms and legs $(2.0 \mathrm{~kg}(7 \%)$ loss of appendicular LM; ALM, a surrogate measure of muscle mass [3]), indicating general rather than localised muscle loss. 
Wilkinson et al. Journal of Rheumatology and Orthopedics 2015,

http://www.hoajonline.com/journals/pdf/2055-7000-2-2.pdf

doi: $10.7243 / 2055-7000-2-2$

Table 1. Change in body composition and disease activity following disease 'flare' and subsequent treatment with intramuscular injection of corticosteroid (triamcinolone acetonide).

\begin{tabular}{llllll}
\hline & $\begin{array}{l}\text { Assessment 1 } \\
\text { (56 days pre-CI) }\end{array}$ & $\begin{array}{l}\text { Assessment 2 } \\
(\mathbf{2 8} \text { days post-CI) }\end{array}$ & $\begin{array}{l}\text { Change: } \\
\text { Assessment 1-2 (\%) }\end{array}$ & $\begin{array}{l}\text { Assessment 3 } \\
(\mathbf{8 6} \text { days post-CI) }\end{array}$ & $\begin{array}{l}\text { Change: } \\
\text { Assessment 2-3 (\%) }\end{array}$ \\
\hline ALM (kg) & 29.4 & 27.4 & $-2.0(-7 \%)$ & 27.8 & $+0.4(+2 \%)$ \\
TLM (kg) & 66.1 & 63.7 & $-2.4(-4 \%)$ & 64.0 & $+0.3(+1 \%)$ \\
TFM (kg) & 22.0 & 21.6 & $-0.4(-2 \%)$ & 21.6 & $0(0 \%)$ \\
Body fat (\%) & 24.2 & 24.5 & $+0.3(+1 \%)$ & 24.5 & $0(0 \%)$ \\
DAS28 score: & 2.91 & 1.54 & $-1.37(-47 \%)$ & $\mathrm{NR}^{\mathrm{b}}$ & $\mathrm{NR}$ \\
- CRP (mg/l) & 8 & $<5^{\mathrm{a}}$ & $\mathrm{NR}$ & $\mathrm{NR}$ & $\mathrm{NR}$ \\
- Tender joints $(n)$ & 1 & 0 & -1 & $\mathrm{NR}$ & $\mathrm{NR}$ \\
- Swollen joints $(n)$ & 1 & 0 & -1 & $\mathrm{NR}$ & $\mathrm{NR}$ \\
- VAS (1-100) & 23 & 0 & -23 & $\mathrm{NR}$ & $\mathrm{NR}$ \\
\hline
\end{tabular}

CI: Corticosteroid injection (40mg triamcinolone acetonide); ALM: Appendicular lean mass (muscle of arms and legs); TLM: Total lean mass; TFM: Total fat mass; DAS28: Disease Activity Score in 28 joints (not measured at Assessment 3); CRP: blood C-reactive protein level; VAS: Visual analogue scale for global health; NR: Not reported. a: CRP at 'Assessment 2' fell below detectable range ( $<5 \mathrm{mg} / \mathrm{l})$; b: no measure of DAS28 was made at 'Assessment 3'

It should be noted that neither TLM nor ALM were restored in the ensuing $\sim 2$ months. This loss of muscle is substantial. To put it into context, a loss of 5\% TLM results in muscle weakness and loss of functional capacity [4]. Further, a recent study performed by our group (manuscript under review) comparing body composition and physical function in RA patients $(n=82)$ with well-controlled disease and healthy age- and sex-matched controls $(n=85)$ revealed that RA patients have $\sim 10 \%$ less muscle mass when ALM is normalised to bodyweight, and this loss coincides with substantial deficits infunction (i.e., 25-35\% poorer performance in objective function tests).

\section{Discussion}

Possible explanations for the LM loss observed following IM CS injection are: i) variance in the DXA measurement; ii) the effect of inflammation during the RA flare (i.e., due to elevated levels of pro-inflammatory cytokines, principally TNF-a [4]); or iii) an effect of the IM CS injection. The effect is unlikely to be related the DXA-measurement. Using data from our trial's placebo arm ( $n=20)$, in-house assessment of our DXA revealed a co-efficient of variation (CV) of $1.4 \%$, which is within the manufacturers recommendation of $\leq 1.5 \%$. Whilst it is possible that the depletion of LM occurred between the onset of flare and the CS injection, this single case report raises the possibility that the IM CS injection, which is regularly used as treatment of active RA, may be contributing to the substantial and sudden loss of muscle mass observed.

Previous evidence on muscular atrophy by IM CS is scarce. A search of the literature revealed only a single case report that subjectively-assessed CS injection-induced local muscle atrophy [5]. Additionally, although the exact mechanisms are unclear, stimulation by CS of the ubiquitin-proteasome system through the increased expression of atrogenes (atrophy genes; such as MuRF-1), as well as inhibition of anabolic pathways (e.g., mTOR/S6 kinase 1 and insulin-like growth factor (IGF)-I), may result in muscle atrophy [6]. If muscle loss is a common iatrogenic effect of IM CS treatment, this is of particular concern for RA patients, as muscle wasting (termed 'rheumatoid cachexia' [4]) characterises the disease and contributes to the reductions in strength and physical function seen in these patients [7].

\section{Conclusions}

In an era in which single high-dose CS injections are, in accordance with National Institute for Health and Care Excellence (NICE) [1] and European League against Rheumatism (EULAR) [8] recommendations, routinely used to treat active disease [2], this incident gives rise to concerns that this standard treatment may be contributing to the deficiency of muscle mass, inherent to rheumatoid cachexia, commonly observed in RA patients $[4,7]$. Thus, it is important to investigate whether the possible iatrogenic effect of acute IM CS injection that we observed is a common response. If this adverse effect is confirmed by an on-going observational study by our group, this raises important concerns about the use of IM CS injection in the treatment of active RA.

\section{Competing interests}

The authors declare that they have no competing interests.

\section{Authors' contributions}

\begin{tabular}{|l|c|c|c|c|}
\hline Authors' contributions & TJW & ABL & TDO & JGJ \\
\hline Research concept and design & -- & $\checkmark$ & $\checkmark$ & $\checkmark$ \\
\hline Collection and/or assembly of data & $\checkmark$ & -- & -- & -- \\
\hline Data analysis and interpretation & $\checkmark$ & $\checkmark$ & $\checkmark$ & $\checkmark$ \\
\hline Writing the article & $\checkmark$ & -- & -- & -- \\
\hline Critical revision of the article & $\checkmark$ & $\checkmark$ & $\checkmark$ & $\checkmark$ \\
\hline Final approval of article & $\checkmark$ & $\checkmark$ & $\checkmark$ & $\checkmark$ \\
\hline Statistical analysis & $\checkmark$ & -- & -- & -- \\
\hline
\end{tabular}


Wilkinson et al. Journal of Rheumatology and Orthopedics 2015, http://www.hoajonline.com/journals/pdf/2055-7000-2-2.pdf

\section{Acknowledgement}

We thank Drs. Y. Ahmed, F. Sheik and S. Chitale (from the Peter Maddison Rheumatology Centre, BCUHB) for being excellent collaborators and providing support to our research.

Publication history

Senior Editor: Gianpaolo Papaccio, Second University of Naples, Italy. Received: 10-Jul-2015 Final Revised: 12-Aug-2015

Accepted: 13-Aug-2015 Published: 17-Aug-2015

\section{References}

1. NICE National Institute for health and Clinical Excellence. Rheumatoid Arthritis - National clinical guideline for management and treatment in adults. NICE Clinical Guideline 79 February 2009. I Website

2. Da Silva JA, Jacobs JW, Kirwan JR, Boers M, Saag KG, Ines LB, de Koning EJ, Buttgereit F, Cutolo M, Capell H, Rau R and Bijlsma JW. Safety of low dose glucocorticoid treatment in rheumatoid arthritis: published evidence and prospective trial data. Ann Rheum Dis. 2006; 65:285-93. | Article | PubMed Abstact | PubMed Full Text

3. Fuller NJ, Wells JC and Elia M. Evaluation of a model for total body protein mass based on dual-energy $\mathrm{X}$-ray absorptiometry: comparison with a reference four-component model. Br J Nutr. 2001; 86:45-52. | Article | PubMed

4. Walsmith $\mathrm{J}$ and Roubenoff R. Cachexia in rheumatoid arthritis. Int J Cardiol. 2002; 85:89-99. | Article | PubMed

5. Park SK, Choi YS and Kim HJ. Hypopigmentation and subcutaneous fat, muscle atrophy after local corticosteroid injection. Korean J Anesthesiol. 2013; 65:S59-61. | Article | PubMed Abstact | PubMed Full Text

6. Schakman O, Kalista S, Barbe C, Loumaye A and Thissen JP. Glucocorticoid-induced skeletal muscle atrophy. Int J Biochem Cell Biol. 2013; 45:2163-72. | Article | PubMed

7. Giles JT, Bartlett SJ, Andersen RE, Fontaine KR and Bathon JM. Association of body composition with disability in rheumatoid arthritis: impact of appendicular fat and lean tissue mass. Arthritis Rheum. 2008; 59:1407-15. | Article | PubMed Abstact | PubMed Full Text

8. Smolen JS, Landewe R, Breedveld FC, Buch M, Burmester G, Dougados M, Emery P, Gaujoux-Viala C, Gossec L, Nam J and Ramiro S et al. EULAR recommendations for the management of rheumatoid arthritis with synthetic and biological disease-modifying antirheumatic drugs: 2013 update. Ann Rheum Dis. 2014; 73:492-509. | Article | PubMed Abstact | PubMed Full Text

\section{Citation:}

Wilkinson TJ, Lemmey AB, O'Brien TD and Jones JG. Significant muscle loss following intramuscular corticosteroid injection used to treat active rheumatoid arthritis: a case report. J Rheumatol Orthop. 2015; 2:2. http://dx.doi.org/10.7243/2055-7000-2-2 